\title{
Presepsin Guidance Reduces the Duration of Antibiotic Treatment in Patients with Sepsis: A Multicenter, Prospective Cohort Trial
}

\section{Hongli Xiao}

Capital Medical University Affiliated Beijing Friendship Hospital

\section{Guoxing Wang}

Capital Medical University Affiliated Beijing Friendship Hospital

\section{Yan Wang}

Capital Medical University Affiliated Beijing Friendship Hospital

\section{Zhimin Tan}

Capital Medical University Affiliated Beijing Friendship Hospital

\section{Xuelian Sun}

Capital Medical University Affiliated Beijing Friendship Hospital

Jie Zhou

Capital Medical University Affiliated Beijing Friendship Hospital

\section{Meili Duan}

Capital Medical University Affiliated Beijing Friendship Hospital

\section{Deyuan Zhi}

Capital Medical University Affiliated Beijing Friendship Hospital

\section{Ziren Tang}

Beijing Chao-Yang Hospital: Beijing Chaoyang Hospital

\section{Chenchen Hang}

Beijing Chao-Yang Hospital: Beijing Chaoyang Hospital

\section{Guoqiang Zhang}

China-Japan Friendship Hospital

\section{Yan Li}

China-Japan Friendship Hospital

\section{Caijun Wu}

Beijing University of Chinese Medicine Affiliated Dongzhimen Hospital

\section{Fengjie Li}

Beijing Luhe Hospital

\section{Haiyan Zhang}

the hospital of Shunyi District Beijing

\section{Jing Wang}


Beijing Xuanwu Hospital: Xuanwu Hospital

\section{Yun Zhang}

Beijing Tongren Hospital Otolaryngology and Head and Neck Surgery Center: Beijing Tongren Hospital

\section{Xinchao Zhang}

Beijing Hospital

\section{Wei Guo}

Beijing Tiantan Hospital

\section{Wenjie Qi}

Capital Medical University Affiliated Beijing Friendship Hospital

\section{Miaorong Xie}

Capital Medical University Affiliated Beijing Friendship Hospital

Chunsheng Li ( $\square$ lcscyyy@163.com)

Deparment of Emergency, Beijing Friendship Hospital, Capital Medical University https://orcid.org/0000-0002-3161-4457

\section{Research}

Keywords: Presepsin, Sepsis, Antibiotics

Posted Date: April 28th, 2021

DOl: https://doi.org/10.21203/rs.3.rs-432564/v1

License: (c) (i) This work is licensed under a Creative Commons Attribution 4.0 International License. Read Full License 


\section{Abstract}

Background: Long-term use of antibiotics for septic patients leads to antibiotic resistance. This study aimed at assessing the benefit and safety of an emerging biomarker presepsin on guiding antibiotic courses for patients with sepsis.

Methods: In this multicenter prospective cohort trial, patients were assigned to the presepsin or control groups. In the presepsin group, antibiotics were ceased based on predefined cut-off ranges of presepsin concentrations. The control group stopped antibiotics according to international guidelines. The primary endpoints were the number of days without antibiotics within 28 days (superiority analysis) and mortality at 28 and 90 days (non-inferiority analysis). The margin of non-inferiority was $10 \%$.

Results: Overall, 656 out of an initial 708 patients were eligible and assigned to the presepsin group $(n=327)$ or the control group $(n=329)$. Patients in the presepsin group had significantly more days without antibiotics than those in the control group (14.54 days [SD 9.01] vs 11.01 days [SD 7.73]; absolute difference 3.64 days, $p=0.000$ ). Mortality in the presepsin group was non-inferior to that in the control group at days 28 (17.7\% vs $18.2 \%$; absolute difference $-0.5 \%, 90 \% \mathrm{Cl}-5.4$ to 4.4$)$ and 90 (19.9\% vs $19.5 \%$; $0.4 \%,-4.7$ to 5.5 ). Patients in the presepsin group had a significantly shorter mean length of stay in the hospital and lower hospitalization costs than control subjects.

Conclusions: Presepsin guidance reduces the duration of antibiotic treatment in patients with sepsis without increasing mortality.

Trial registration: ChiCTR, ChiCTR1900024391. Registered 9 July 2019. Retrospectively registered.

\section{Introduction}

Sepsis is a life-threatening organ dysfunction caused by host's maladjustment to infection. Antibiotic therapy is recommended to be administered within 1 hour after the diagnosis of sepsis [1]. However, the optimal duration of antibiotic treatment is at the doctor's discretion based on treatment guidelines. Thus, long-term use of antibiotics is frequently seen in real clinical setting [2]. Antibiotic resistance related with long-term application of antibiotics may affect patients' outcomes and healthcare resources [3].

Biomarkers reflecting the infection resolution is promising for an individualized guidance for antibiotic duration. Regularly suggested biomarkers for infection resolution include C-reactive protein (CRP) and procalcitonin (PCT) [4-6]. However, large studies evaluating the values of PCT or CRP for guiding the duration of antibiotic treatment provided controversial results [7-11]. Recently, presepsin has been proven to be a valuable biomarker for diagnosing the presence [12], severity [13, 14] or prognosis [14] of sepsis. It seems be superior to PCT and CRP for the diagnosis and prognosis of sepsis $[15,16]$. Presepsin is a subtype of soluble CD14 formed by a 13-kDa fragment [17]. CD14 is a glycoprotein receptor for lipopolysaccharide (LPS)/LPS binding protein complexes mainly expressed on the surface of monocyte macrophages and plays an important role in the systemic inflammatory response syndrome (SIRS) 
mediated by LPS [18]. Masson et al. [19] explored the potential of presepsin as a biomarker in sepsis and found that presepsin levels tended to increase in patients with positive microbiology and inappropriate antibiotic therapy. Increasing evidence suggests the potentially promising strategies of presepsin-directed antibiotic escalation and de-escalation [19]. However, whether presepsin guidance could reduce the duration of antibiotic treatment and its safety have never been determined. Therefore, we performed a multicenter, prospective cohort study to assess the benefit and safety of presepsin-guided antibiotic treatment in patients with sepsis.

\section{Materials And Methods}

\section{Study design}

A prospective, multicenter, cohort trial was conducted in the emergency intensive care unit (EICU), general intensive care unit (ICU) and infectious disease department of ten university-affiliated teaching hospitals in China between November 2017 and December 2019. This study was approved by the ethics committee of Beijing Friendship Hospital affiliated to Capital Medical University (2017-P2-103-02) and has been registered in Chinese Clinical Trial Registry (ChiCTR1900024391).

\section{Patients}

The inclusion criteria were as follows: 1) at least 18 years of age, 2) met diagnostic criteria for sepsis or septic shock (Sepsis-3) [20], 3) admitted to the hospital or ICU within 24 hrs, 4) received antibiotics with the presepsin levels at least $350 \mathrm{pg} / \mathrm{ml}$. Patients who developed sepsis during their stay in hospital were also assessed for enrollment. The exclusion criteria included prolonged therapy (eg, liver abscess, infective endocarditis), expected stay in hospital or ICU of less than 2 days, pregnancy, cancer.

Written informed consent was obtained from all participants. Patients were assigned to the control group in odd-numbered days, and to the presepsin group in even-numbered days. Patients and investigators were aware of treatment assignment. A unified case report form was used to record patient information. All investigators were trained and registered by the coordinating center. A specially assigned coordinator was responsible for supervising the quality of data collection. All investigators were unaware of aggregate outcomes. The patients were followed up for 28 days and 90 days.

\section{Data collection and definitions}

Data were recorded at baseline after inclusion and thereafter every other day during the follow-up. Collected data included age, sex, vital signs, admission category, comorbidities, indicators of severity [sequential organ-failure assessment (SOFA) score, acute physiology and chronic health evaluation $($ APACHE) $\square$ score (at inclusion only), disseminated intravascular coagulation (DIC) score (at inclusion only), organ or system failure [21], septic shock [20], serum lactate], reason for admission to ICU, type of infection (community-acquired or hospital-acquired infection), infection site, pathogen culture, interventions [vasoactive drugs, noninvasive or mechanical ventilation, continuous renal replacement 
therapy (CRRT), extracorporeal membrane oxygenation], antibiotics and biomarkers (PCT and CRP). Multidrug-resistant bacteria were defined as resistance to three or more antibiotics at the same time [7].

\section{Presepsin measurements}

For presepsin measurements, venous blood samples were obtained and collected in tubes containing heparin after inclusion and thereafter every other day between 5:00 $\mathrm{AM}$ and 6:00 $\mathrm{AM}$, stored at $-80^{\circ} \mathrm{C}$, and then tested between 7:00 AM and 8:00 AM using a compact automated immunoanalyzer (PATHFAST; Mitsubishi Chemical Medience Corporation, Tokyo, Japan) based on a chemiluminescent enzyme immunoassay [22] by a project coordinator who was blinded to the patient groups, but not the clinicians. This test has a normal reference range of $20-200000 \mathrm{pg} / \mathrm{ml}$. Attending physicians in the presepsin group but not the control group were informed of the results before 8 AM. PCT and CRP, were concurrently measured after inclusion and every other day as part of the standard of care in all patients.

\section{Procedures}

The attending physician was advised to stop the antibiotics if the blood presepsin concentration was lower than $350 \mathrm{pg} / \mathrm{ml}$ or decrease by $80 \%$ or more compared with the value at the first day for two consecutive times (initial stopping threshold). Two days later, the physician continued to stop the antibiotics if the blood presepsin concentration was lower than $350 \mathrm{pg} / \mathrm{ml}$ or decrease by $80 \%$ or more from peak concentration and no obvious sign of infection exhibited (final stopping threshold). Otherwise, reassumption of antibiotics was required. Antibiotic adjustment (sensitive to bacteria, if the blood culture is positive) was encouraged when the blood presepsin concentration had no decline compared with the first day and more than $350 \mathrm{pg} / \mathrm{ml}$ for 3 consecutive times (Fig. 1). The physician was free to decide whether to stop antibiotics in patients who had reached these thresholds. Antibiotics in the control group were guided according to the current clinical guidelines [23] and discretion of physicians for patient's condition.

\section{Outcomes}

The primary outcomes were the number of days without antibiotics during 28 days after inclusion and 28-day and 90-day mortality during the follow-up. Secondary outcomes were the percentage of patients with a recurrent infection within 90 days, length of stay in ICU and hospital, hospitalization costs, days of first episode of antibiotic treatment within the 28 days, percentage of antibiotic administration and multidrug-resistant bacteria, and SOFA score.

\section{Statistical analysis}

The aim of this trial was to determine whether the presepsin-guided strategy was superior in the duration of antibiotic treatment, as estimated by the number of days without antibiotics during 28 days, and its non-inferiority in terms of 28-day and 90-day mortality. For the superiority test, we assumed a mean of 11.6 days and an SD of 8.2 days without antibiotics for the control group [7]. With a two-sided of $a=0.05$ and $\mathrm{a} \beta$ of 0.1 and a 2.7-day increase in the number of days without antibiotics [7], we would need 130 
patients per study group. For the non-inferiority test, we assumed $30 \%$ mortality for the control group [7]. With a $10 \%$ a-risk and a $\beta$ of 0.2 and a $10 \%$ margin for presepsin-guided treatment regarding mortality, we would need 280 patients per study group. The study required 700 patients to account for $20 \%$ patients lost to follow up.

Statistical analyses were performed using SPSS, version 20 (IBM software). Comparability of the presepsin group and the control group was analyzed by the chi-square test (categorical variables), student's $t$ tests or Mann-Whitney U test (continuous variables) as appropriate. For the primary outcome of mortality, the absolute difference of mortality between the two study groups was calculated with twosided $90 \% \mathrm{Cl}$ (non-inferiority analysis). In addition, the absolute mean difference of number of days without antibiotics between the two study groups was estimated with a univariate general linear model and calculation of $95 \% \mathrm{Cl}$ for this mean difference (superiority analysis). The comparison of accuracy of the presepsin, PCT and CRP in prediction of stopping antibiotics within 28 days was assessed by the areas under the receiver operating characteristic curves (AUCs). The independent risk factors of death were determined by Binary Logistic regression. Time-to-event analyses were estimated by Kaplan-Meier survival curves and Cox proportional hazards models.

\section{Results}

\section{Baseline characteristics}

A total of 708 patients with sepsis and a presepsin level $\geq 350 \mathrm{pg} / \mathrm{ml}$ were screened in the 10 participating ICUs and infectious disease departments from November 29, 2017 to December 12, 2019.

Of these, 14 patients were excluded and 694 were enrolled and assigned to the presepsin group $(n=345$ patients) or the control group ( $n=349$ patients). A total of 38 patients were lost to follow-up. Finally, 656 patients were eligible and divided in the presepsin $(n=327)$ and control $(n=329)$ groups (Fig. 2$)$. The baseline clinical characteristics were comparable between the two groups (see Additional Table 1). 
Table 1

Main Outcome Variables

Variables
Presepsin group $(n=327)$
Control group (n = 329)
Between-group

absolute difference

in means $(95 \% \mathrm{Cl})$

\section{Primary endpoints}

Number of days without antibiotics

28-day mortality*
90-day mortality*
Secondary endpoints(days1-
$90)$

Recurrent infection

$9(2.75 \%)$

$10(3.04 \%)$

$-0.3 \%(-2.9-2.3)$

0.827

Length of stay in ICU from inclusion (days)

$11.17(9.70)$

$14.16(11.23)$

$-2.99(-5.06--0.93)$

0.005

Length of stay in hospital

from inclusion (days)

$12(10.77)$

$14.74(10.50)$

$-2.73(-4.36--1.10)$

0.001

Hospitalization costs

36032.13

(21304.67-

74125.03)

43430.02

(25623.12-

94632.76)

NA

0.021

Duration of first episode of

antibiotic treatment (days)

Overall population

$9.86(6.53)$

$13.42(6.72)$

$-3.56(-4.57--2.54)$

0.000

Respiratory tract infection

$10.74(7.68)$

14.68 (8.19)

$-3.94(-5.61--2.27)$

0.000

Gastrointestinal tract

10.7 (6.62)

$12.42(7.47)$

$-1.71(-5.57-2.13)$

0.375

Urinary tract

$13.33(9.11)$

$15.57(8.13)$

$-2.23(-5.95-1.49)$

0.236

Biliary tract

$8.36(3.64)$

$12.57(4.10)$

$-4.21(-5.16--3.25)$

0.000

CNS

7.5 (3.53)

22.71 (7.78)

$-15.2(-29.11--1.32)$

0.036

Skin infection

11.43 (9.72)

11.66 (14.15)

$-0.23(-17.74-17.27)$

0.976

Positive blood culture

Yes

$14.4(1.15)$

$13.89(1.06)$

$0.51(-3.18-4.20)$

0.783

Data are mean (SD), difference $(95 \% \mathrm{Cl})$, number (\%), or median (IQR). Between-group absolute differences were calculated using the mean values, percentage differences, and $95 \% \mathrm{Cls}$. NA = not applicable. *Difference $(90 \% \mathrm{Cl})$.

ICU: intensive care unit, CNS: central nervous system, SOFA: sequential organ failure assessment 


\begin{tabular}{|c|c|c|c|c|}
\hline Variables & $\begin{array}{l}\text { Presepsin group } \\
(n=327)\end{array}$ & $\begin{array}{l}\text { Control group (n } \\
=329)\end{array}$ & $\begin{array}{l}\text { Between-group } \\
\text { absolute difference } \\
\text { in means }(95 \% \mathrm{Cl})\end{array}$ & $p$ \\
\hline No & $9.37(0.38)$ & $13.36(0.38)$ & $-3.99(-5.03--2.95)$ & 0.000 \\
\hline \multicolumn{5}{|l|}{$\begin{array}{l}\text { Antibiotic exposure rate at } \\
28 \text { days follow-up }\end{array}$} \\
\hline$\beta$-lactam antibiotics & 301 (92.0\%) & $317(96.4 \%)$ & $-4.3 \%(-7.9--0.7)$ & 0.018 \\
\hline Glycopeptide & $77(23.5 \%)$ & $111(33.7 \%)$ & $-10.2 \%(-17.1--3.3)$ & 0.004 \\
\hline Quinolones & $64(19.6 \%)$ & $55(16.7 \%)$ & $2.9 \%(-3.1-8.8)$ & 0.343 \\
\hline Aminoglycoside & $26(8.0 \%)$ & $22(6.7 \%)$ & $1.3 \%(-2.7-5.3)$ & 0.534 \\
\hline Tetracycline & $13(4.0 \%)$ & $17(5.2 \%)$ & $-1.2 \%(-4.4-2.0)$ & 0.465 \\
\hline Macrolide & $4(1.2 \%)$ & $4(1.2 \%)$ & $0.01 \%(-1.7-1.7)$ & 0.993 \\
\hline Sulfonamides & $3(0.9 \%)$ & $3(0.9 \%)$ & $0.01 \%(-1.5-1.5)$ & 0.994 \\
\hline Antifungal drugs & $32(9.8 \%)$ & $46(14.0 \%)$ & $-4.2 \%(-9.2-0.8)$ & 0.097 \\
\hline Antiviral drugs & $11(3.4 \%)$ & $14(4.3 \%)$ & $-0.9 \%(-3.8-2.0)$ & 0.551 \\
\hline Multidrug-resistant bacteria & $40(12.2 \%)$ & $46(14.0 \%)$ & $-1.7 \%(-6.9-3.4)$ & 0.507 \\
\hline \multicolumn{5}{|l|}{ SOFA score } \\
\hline Day 1 & $4.46(3.11) / 307$ & $4.91(3.84) / 298$ & $-0.45(-1-0.1)$ & 0.115 \\
\hline Day 7 & $3.13(3.38) / 181$ & $2.77(3.67) / 221$ & $0.36(-0.34-1.05)$ & 0.313 \\
\hline Day 13 & $3.75(3.53) / 44$ & $3.27(4.29) / 77$ & $0.47(-1.03-1.98)$ & 0.533 \\
\hline Day 19 & $7.08(4.62) / 12$ & $6.38(5.08) / 18$ & $0.69(-3.05-4.44)$ & 0.707 \\
\hline Day 25 & $8(\mathrm{NA}) / 1$ & $8(7.87) / 4$ & $0(28.01-28.01)$ & 1.000 \\
\hline \multicolumn{5}{|c|}{$\begin{array}{l}\text { Data are mean }(\mathrm{SD}) \text {, difference }(95 \% \mathrm{Cl}) \text {, number }(\%) \text {, or median }(\mathrm{IQR}) \text {. Between-group absolute } \\
\text { differences were calculated using the mean values, percentage differences, and } 95 \% \mathrm{Cls} \text {. NA = not } \\
\text { applicable. *Difference }(90 \% \mathrm{Cl}) \text {. }\end{array}$} \\
\hline \multicolumn{5}{|c|}{ ICU: intensive care unit, CNS: central nervous system, SOFA: sequential organ failure assessment } \\
\hline
\end{tabular}

\section{Adherence To Antibiotic Strategies}

Antibiotic strategy adherence was recorded for 276 (84.4\%) patients in the presepsin group. In the remaining 51 patients in the presepsin group, physicians stopped antibiotics in 38 patients before reaching the stopping rules because they regarded the infection as clinically cured. For 13 out of 51 patients, physicians continued antibiotics based upon achievement of the stopping standard because of 
clinical instability ( 3 patients, 2 with infection by multidrug-resistant bacteria) and ward transfer. As expected, the recurrence rate among patients who stopped antibiotics before reaching the suspension standard was significantly higher than that among those who did not (10.5\% vs. $1.7 \%, p=0.013)$. One death during 28 days and 3 deaths during 90 days were recorded as related to recurrent infection.

\section{Primary Outcome}

The duration of antibiotic treatment within the 28 days in the presepsin group was lowered by $33.1 \%$ compared to the control group (Table 1). The absolute mean difference of days free of antibiotics in 28 days between groups was 3.64 days $(p=0.000)$. The 28 -day and 90 -day mortality rates in the presepsin group were non-inferior to those in the control group, and the Kaplan-Meier analyses of 28-day and 90day survival probability showed no differences between the two groups (Fig. 3, A and B). Patients in the presepsin group had similar mean survival time in 28 days and 90 days with control subjects $(24.57 \mathrm{~d}$ vs. $24.45 \mathrm{~d}$ for 28 days; $74.92 \mathrm{~d}$ vs. $74.87 \mathrm{~d}$ for 90 days, respectively).

After adjustment for age and gender, the odds ratio for death in the presepsin group compared with the control group was $0.96(90 \% \mathrm{Cl} 0.71-1 \cdot 31)$ for day 28 and $1.01(0.76-1.36)$ for day 90 . After adjustment for multiple independent factors of death (septic shock, immunosuppressant, APACHEX score and infection site of pulmonary), the odds ratio was 0.97 (90\% $\mathrm{Cl} 0.70-1.34)$ for day 28 , and 1.02 (0.74-1.39) for day 90 .

\section{Secondary Outcome}

The presepsin group had a significantly shorter mean length of ICU stay and hospital stay than control subjects as well as a tendency to have lower hospitalization costs. The mean antibiotic duration for the first infectious episode was significantly shorter in the presepsin group than in the control group for the overall population. Same tendency was observed for patients with respiratory tract infections, biliary tract infections, central nervous system (CNS) infections and negative blood cultures (Table 1).

Patients in the presepsin group had a significantly shorter median duration of first episode of antibiotic treatment than those in the control group ( $9 \mathrm{~d}$ vs. $13 \mathrm{~d} ; p=0.000$, Fig. $3 \mathrm{C}$ ). The probability of antibiotic suspension within 28 days in presepsin group was 1.72 times higher than that in the control group $(95 \% \mathrm{Cl} 1.44-2.06 ; p=0.000)$ and 1.74 times after adjusting for age and gender $(95 \% \mathrm{Cl} 1.45-2.08 ; p=$ 0.000). Interestingly, more men in the presepsin group seemed to cease antibiotics compared with the control group ( $76.3 \%$ vs. $67.9 \%, p=0.06)$, but not the women $(78.5 \%$ vs. $79.1 \%, p=0.893)$. The same tendency was observed in that men were $30.9 \%$ less likely to stop antibiotics than women in the control group ( $p=0.005,95 \% \mathrm{Cl} 0.536-0.893)$, but not in the presepsin group $(p=0.598,95 \% \mathrm{Cl} 0.721-1.207)$.

During 28-day follow-up, the rate of antibiotic use in the presepsin group was significantly lower than the control group, especially broad-spectrum antibiotics and advanced antibiotics such as $\beta$-lactam 
antibiotics and glycopeptide antibiotics (Table 1). There were no differences in the rate of recurrent infection and multidrug-resistant bacteria and the SOFA score between the two groups.

\section{Subgroup Analysis Between Groups}

In subgroups of CNS infection, skin infection, positive blood culture, septic shock, immunocompromise, diabetes, chronic renal failure (CRF), cirrhosis, connective tissue disease and SOFA score at inclusion $\geq 7$, the duration of antibiotic treatment was not significantly shorter in the presepsin group than in the control group. However, the duration of antibiotic treatment was slightly shorter in the following subgroups: hospital-acquired, urinary tract infection, vasoactive drugs and chronic obstructive pulmonary disease (see Additional Table 2). In addition, the 90-day mortality in the presepsin group was non-inferior to that in the control group, but not for some subgroups (see Additional Table 3).

\section{Comparing Presepsin With Pct And Crp In Guiding Antibiotics}

In order to compare the efficacy of presepsin, PCT and CRP in guiding antibiotic suspension during 28 days, the AUC from ROC curve analysis was used, and the results showed that the AUC of presepsin on day 9 (presepsin 9th) was $0.926(95 \% \mathrm{Cl} 0.863-0.988, p=0.000)$, which was higher than that for PCT 11th $(0.883,95 \% \mathrm{Cl} 0.789-0.977, p=0.000)$ and CRP 9 th $(0.867,95 \% \mathrm{Cl} 0.767-0.967, p=0.000)$ (see Additional Fig. 1). The optimal predictive thresholds were $622.50 \mathrm{pg} / \mathrm{ml}$ for presepsin 9 th (sensitivity $100.0 \%$ and specificity $84.3 \%$ ), $0.96 \mu \mathrm{g} / \mathrm{L}$ for PCT 11 th (sensitivity $78.6 \%$ and specificity $84.3 \%$ ) and 32.94 $\mathrm{mg} / \mathrm{L}$ for CRP 9th (sensitivity $92.9 \%$ and specificity $74.5 \%$ ). The probability of antibiotic suspension during 28 days for those with presepsin 9th levels lower than $622.50 \mathrm{pg} / \mathrm{ml}$ was 3.22 times that for those with levels higher than $622.50 \mathrm{pg} / \mathrm{ml}(95 \% \mathrm{Cl} 2.25-4.61, p=0.000)$. The Kaplan-Meier survival curves for presepsin 9th, PCT 11th and CRP 9th are shown in Additional Fig. 2.

\section{Discussion}

Presepsin is a novel biomarker for the diagnosis of bacterial infections [24, 25], especially Gram-negative organisms. Elevated presepsin level has been confirmed to be associated with the severity [26], number of organs dysfunction [27], ICU death and death before 90 days of sepsis [19, 28]. However, whether presepsin could guide antibiotic strategies for septic patients has not yet been studied. The ALBIOS substudy proposed that presepsin may be valuable to guide therapy in sepsis [19]. Our findings to the best of our knowledge demonstrated for the first time that presepsin guidance could safely reduce the duration of antibiotic treatment.

Our findings revealed that presepsin guidance could reduce the duration of antibiotic treatment by 3.64 days in septic patients. Although controversial results existed [29, 30], previous large randomized controlled trials, the PRORATA and SAPS trails, aimed to assess whether PCT reduced antibiotic exposure 
showed that a PCT-guided strategy could similarly reduce antibiotic duration by 2.7 or 1.22 days without obvious adverse outcomes in critically ill patients, respectively $[7,8]$.

The prognostic effect of presepsin on sepsis was also evaluated in the current study. The results showed that antibiotic guidance with presepsin did not have a detrimental effect on 28-day and 90-day survival, which seemed to be superior to other conventional infection-related biomarkers such as PCT. PCT has been widely studied for the diagnosis [31] and outcome prediction [32]. In the PASS trial, PCT-guided antimicrobial escalation did not improve survival, and lead to organ-related harm and prolonged admission to the ICU [9]. On the contrary, in the SAPS study, PCT guidance reduced the 28-day and 1-year mortality which might be attributed to a prompt diagnosis and initiation of antibiotics [8]. However, presepsin in this study was not used to guide the initiation of antibiotic treatment.

The secondary outcome analyses in the current study revealed that presepsin guidance decreased length of ICU and hospital stay and hospitalization costs. Moreover, antibiotic adjustment based on presepsin did not affect recurrence rate of infection. These findings are in accordance with the PRORATA trial [7]. Evelien et al. [8] showed that $16(26 \%)$ of 61 patients with a recurrent infection had a short initial duration of antibiotics. Thus, we found that early discontinuation of antibiotics before reaching suspension requirements may increase the recurrence rate of infection (from 1.7-10.5\%). As expected, shorter antibiotic duration for the first infectious episode [8,33] and decreased antimicrobial exposure [34] especially $\beta$-lactam antibiotics and glycopeptide antibiotics were observed. The presepsin group was almost twice as likely to stop antibiotics as the control group during 28 days. Despite lower antibiotic exposure in the presepsin group than in the control group, the rates of multidrug-resistant bacteria showed no difference as a result of unavoidable nosocomial cross infection. An interesting finding was that presepsin guidance seemed to be more beneficial to male patients. which needs further evaluation.

There are several limitations in this study. First, the design was not randomized although this was a multicenter and prospective study. Second, the ideal threshold for stopping antibiotics has not been determined. In previous clinical trials, the presepsin cut-off for diagnosing sepsis ranged from 317 to 700 $\mathrm{pg} / \mathrm{ml}$ [35]. The reference range for normal populations and the diagnostic cut-off value of sepsis were considered in the determination of optimal cut-off values to trigger discontinuation of antibiotics. According to the English instructions, the presepsin values range from 60 to $365 \mathrm{pg} / \mathrm{ml}$ with a 95th percentile of $320 \mathrm{pg} / \mathrm{ml}$ in healthy individuals. Based on the Japanese instructions, the normal reference value is $314 \mathrm{pg} / \mathrm{ml}$ and the cut-off value for diagnosis of sepsis is $500 \mathrm{pg} / \mathrm{ml}$. In our previous study, the presepsin cut-off value was $317 \mathrm{pg} / \mathrm{ml}$ for diagnosing sepsis and $449 \mathrm{pg} / \mathrm{ml}$ for predicting severe sepsis based on the diagnostic criteria of sepsis 2.0 based on the diagnostic criteria of sepsis $2.0[26,36]$. Carpio et al. reported cut-off values for diagnosing sepsis ( $300 \mathrm{pg} / \mathrm{mL}$ to $500 \mathrm{pg} / \mathrm{mL}$ ) [37]. It would be too early to stop antibiotics based on the diagnostic value of presepsin for sepsis (500 or $449 \mathrm{pg} / \mathrm{ml}$ ) as mentioned above, since these patients are still at high risk of infection. However, a presepsin value of 320 $\mathrm{pg} / \mathrm{ml}$ (95th percentile of the normal level) is too low to guide antibiotic discontinuation. Therefore, we chose $350 \mathrm{pg} / \mathrm{ml}$ as the optimal and low-risk cutoff value to trigger discontinuation of antibiotics. Third, from the subgroup analysis, we found that presepsin could not guide the use of antibiotics in special 
populations such as those with positive blood culture, septic shock, SOFA score more than 7 and immune compromise. For these patients, physician preferred to extend the duration of antibiotic treatment due to severe infection or unstable condition. For patients with a relatively severe condition (hospital-acquired infection, mechanical ventilation, vasoactive drugs, CRRT, septic shock, chronic heart failure and positive blood culture), immunocompromised and diabetic patients, insufficient evidence for non-inferiority of presepsin guidance on 28-day and 90-day mortality was observed. In this study, we identified the septic patients suitable to use of presepsin for guiding antibiotic therapy. Fourth, the differences on the predictive efficiency for sepsis among presepsin and other potential biomarkers need to be further evaluated in large-scale randomized control trials [38, 39].

\section{Conclusions}

This multicenter study validated that presepsin guidance could reduce the duration of antibiotic treatment in patients with sepsis without increasing recurrent infection rate and 28-day or 90-day mortality. Moreover, the guidance strategy based on presepsin shortened the length of stay in ICU or hospital and reduced hospitalization costs.

\section{Abbreviations}

CRP: C-reactive protein; PCT: Procalcitonin; LPS: Lipopolysaccharide; SIRS: Systemic inflammatory response syndrome; EICU: Emergency intensive care unit; SOFA: Sequential organ-failure assessment; APACHE: Acute physiology and chronic health evaluation; DIC: Disseminated intravascular coagulation; CRRT: Continuous renal replacement therapy; CNS: Central nervous system; CRF: Chronic renal failure; AUC: Area under the receiver operating characteristic curve.

\section{Declarations}

\section{Acknowledgements}

We thank Drs. Jiandong Zhang, Jie Yang, Shuai Xia, Meiying Zhang, Sijia Wang and Zheng Wang for collecting cases. We also thank Dr Shanshan Wu for statistical analyses and Medjaden Bioscience Limited for polishing the manuscript. And we gratefully acknowledge all health care workers on the front line and all patients involved in the study.

\section{Authors' contributions}

CSL, MRX, HLX and GXW contributed to the conception and design of the study, had full access to all the data in the study and take responsibility for the integrity of the data and the accuracy of the data analysis. HLX, GXW, YW, ZMT, XLS, JZ, MLD, DYZ, ZRT, CCH, GQZ, YL, CJW, FJL, HYZ, JW, YZ, XCZ, WG and WJQ contributed to the acquisition of data. CSL, MRX, HLX and GXW contributed to the analysis and interpretation of the data. HLX and CSL contributed to the statistical analyses. HLX and CSL drafted the 
manuscript and revised it critically for important intellectual content. All authors read and approved the final manuscript. Drs. HLX and GXW contributed equally and share first authorship.

\section{Funding}

This work was supported by the Beijing Municipal Administration of Hospitals Clinical Medicine Development of Special Funding Support "Yangfan" Project (ZYLX201802), the Beijing Municipal Administration of Hospitals' Youth Program (QML20170105), as well as the National Natural Science Foundation of China (81374004 and 81773931). The funding source had no role in the design and conduct of the study, the analysis and interpretation of the data, or in the writing of the manuscript.

\section{Availability of data and materials}

All data generated or analyzed during this study are included in this article.

\section{Ethical approval}

This study was approved by the Ethics Commission of Beijing Friendship Hospital affiliated to Capital Medical University (2017-P2-103-02).

\section{Consent for publication}

Not applicable.

\section{Competing interests}

All authors declare no competing interests.

\section{References}

1. Buckman SA, Turnbull IR, Mazuski JE. Empiric Antibiotics for Sepsis. Surg Infect (Larchmt). 2018;19:147 - 54.

2. Rice LB. The Maxwell Finland lecture: for the duration-rational antibiotic administration in an era of anti-microbial resistance and Clostridium difficile. Clin Infect Dis. 2008;46:491-6.

3. Kollef MH, Fraser VJ. Antibiotic resistance in the intensive care unit. Ann Intern Med. 2001;134:298314.

4. Simon L, Gauvin F, Amre DK, Saint-Louis P, Lacroix J. Serum procalcitonin and C-reactive protein levels as markers of bacterial infection: a systematic review and meta-analysis. Clin Infect Dis. 2004;39:206-17.

5. Tang BMP, Eslick GD, Craig JC, McLean AS. Accuracy of procalcitonin for sepsis diagnosis in critically ill patients: systematic review and meta-analysis. Lancet Infect Dis. 2007;7:210-17.

6. Becker KL, Snider R, Nylen ES. Procalcitonin assay in systemic inflammation, infection, and sepsis: clinical utility and limitations. Crit Care Med. 2008;36:941-52. 
7. Bouadma L, Luyt CE, Tubach F, Cracco C, Alvarez A, Schwebel C, Schortgen F, Lasocki S, Veber B, Dehoux M. et al. Use of procalcitonin to reduce patients' exposure to antibiotics in intensive care units (PRORATA trial): a multicentre randomised controlled trial. Lancet. 2010;375:463-74.

8. de Jong E, van Oers JA, Beishuizen A, Vos P, Vermeijden WJ, Haas LE, Loef BG, Dormans T. van Melsen GC, Kluiters $Y C$, et al. Efficacy and safety of procalcitonin guidance in reducing the duration of antibiotic treatment in critically ill patients: a randomised, controlled, open-label trial. Lancet Infect Dis. 2016; 16: 819 - 27.

9. Jensen JU, Hein L, Lundgren B, Bestle MH, Mohr TT, Andersen MH, Thornberg KJ, Løken J, Steensen $M, F o x Z$. et al. Procalcitonin-guided interventions against infections to increase early appropriate antibiotics and improve survival in the intensive care unit: a randomized trial. Crit Care Med. 2011;39:2048-58.

10. Kopterides P, Siempos II, Tsangaris I, Tsantes A, Armaganidis A. Procalcitonin-guided algorithms of antibiotic therapy in the intensive care unit: a systematic review and meta-analysis of randomized controlled trials. Crit Care Med. 2010;38:2229-41.

11. Borges I, Carneiro R, Bergo R, Martins L, Colosimo E, Oliveira C, Saturnino S, Andrade MV, Ravetti C, Nobre $V$. et al. Duration of antibiotic therapy in critically ill patients: a randomized controlled trial of a clinical and C-reactive protein-based protocol versus an evidence-based best practice strategy without biomarkers. Crit Care. 2020;24:281.

12. Kweon OJ, Choi JH, Park SK, Park AJ. Usefulness of presepsin (SCD14 subtype) measurements as a new marker for the diagnosis and prediction of disease severity of sepsis in the Korean population. $J$ Crit Care. 2014;29:965-70.

13. Behnes M, Bertsch T, Lepiorz D, Lang S, Trinkmann F, Brueckmann M, Borggrefe M, Hoffmann U. Diagnostic and prognostic utility of soluble CD 14 subtype (presepsin) for severe sepsis and septic shock during the first week of intensive care treatment. Crit Care. 2014;18:507.

14. Liu B, Yin Q, Chen YX, Zhao YZ, Li CS. Role of presepsin (sCD14-ST) and the CURB65 scoring system in predicting severity and outcome of community-acquired pneumonia in an emergency department. Respir Med. 2014;108:1204-13.

15. Ruan L, Chen GY, Liu Z, Zhao Y, Xu GY, Li SF, Li CN, Chen LS, Tao Z. The combination of procalcitonin and $\mathrm{C}$-reactive protein or presepsin alone improves the accuracy of diagnosis of neonatal sepsis: a meta-analysis and systematic review. Crit Care. 2018;22:316.

16. Yu H, Qi Z, Hang C, Fang Y, Shao R, Li C. Evaluating the value of dynamic procalcitonin and presepsin measurements for patients with severe sepsis. Am J Emerg Med. 2017;35:835 - 41.

17. Shirakawa K, Naitou K, Hirose J, Takahashi T, Furusako S. Presepsisn. (sCD14-ST): development and evaluation of one-step ELISA with a new standard that is similar to the form of presepsin in septic patients. Clin Chem Lab Med. 2011;49:937-9.

18. Karakioulaki M, Stolz D. Biomarkers in pneumonia-beyond procalcitonin. Int J Mol Sci. 2019;20:204.

19. Masson S, Caironi P, Fanizza C, Thomae R, Bernasconi R, Noto A, Oggioni R, Pasetti GS, Romero M, Tognoni G. et al. Circulating presepsin (soluble CD14 subtype) as a marker of host response in 
patients with severe sepsis or septic shock: data from the multicenter, randomized ALBIOS trial. Intensive Care Med. 2015;41:12-20.

20. Singer M, Deutschman CS, Seymour CW, Shankar-Hari M, Annane D, Bauer M, Bellomo R, Bernard GR, Chiche JD, Coopersmith CM. et al. The Third International Consensus Definitions for Sepsis and Septic Shock (Sepsis-3). JAMA. 2016;315:801 - 10.

21. Vincent JL. de Mendonça A, Cantraine F, Moreno R, Takala J, Suter PM, Sprung CL, Colardyn F, Blecher S. Use of the SOFA score to assess the incidence of organ dysfunction/failure in intensive care units: results of a multicenter, prospective study. Working group on "sepsis-related problems" of the European Society of Intensive Care Medicine. Crit Care Med. 1998; 26: 1793-800.

22. Okamura Y, Yokoi H. Development of a point-of-care assay system for measurement of presepsin (sCD14-ST). Clin Chim Acta. 2011;412:2157-61.

23. Rhodes A, Evans LE, Alhazzani W, Levy MM, Antonelli M, Ferrer R, Kumar A, Sevransky JE, Sprung CL, Nunnally ME. et al. Surviving Sepsis Campaign: International Guidelines for Management of Sepsis and Septic Shock: 2016. Intensive Care Med. 2017;43:304-77.

24. Qi ZJ, Yu H, Zhang J, Li CS. Presepsin as a novel diagnostic biomarker for differentiating active pulmonary tuberculosis from bacterial community acquired pneumonia. Clin Chim Acta. 2018;478:152-6.

25. Kang J, Gong P, Zhang XD, Wang WJ, Li CS. Early Differential Value of Plasma Presepsin on Infection of Trauma Patients. Shock. 2019;52:362-9.

26. Liu B, Chen YX, Yin Q, Zhao YZ, Li CS. Diagnostic value and prognostic evaluation of Presepsin for sepsis in an emergency department. Crit Care. 2013;17:R244.

27. Nakamura $Y$, Ishikura H, Nishida T, Kawano $Y$, Yuge R, Ichiki R, Murai A. Usefulness of presepsin in the diagnosis of sepsis in patients with or without acute kidney injury. BMC Anesthesiol. 2014;14:88.

28. Kerr KF, Wang Z, Janes H, McClelland RL, Psaty BM, Pepe MS. Net reclassifification indices for evaluating risk prediction instruments: a critical review. Epidemiology. 2014;25:114-21.

29. Masson S, Caironi P, Spanuth E, Thomae R, Panigada M, Sangiorgi G, Fumagalli R, Mauri T, Isgrò S, Fanizza C, et al. Presepsin (soluble CD14 subtype) and procalcitonin levels for mortality prediction in sepsis: data from the albumin Italian outcome sepsis trial. Crit Care. 2014;18:R6.

30. Jung B, Molinari N, Nasri M, Hajjej Z, Chanques G, Jean-Pierre H, Panaro F, Jaber S. Procalcitonin biomarker kinetics fails to predict treatment response in perioperative abdominal infection with septic shock. Crit Care. 2013;17:R255.

31. Wacker C, Prkno A, Brunkhorst FM, Schlattmann P. Procalcitonin as a diagnostic marker for sepsis: a systematic review and meta-analysis. Lancet Infect Dis. 2013;13:426-35.

32. Jensen JU, Heslet L, Jensen TH, Espersen K, Steffensen P, Tvede M. Procalcitonin increase in early identifification of critically ill patients at high risk of mortality. Crit Care Med. 2006;34:2596-602.

33. Nobre V, Harbarth S, Graf JD, Rohner P, Pugin J. Use of procalcitonin to shorten antibiotic treatment duration in septic patients: a randomized trial. Am J Respir Crit Care Med. 2008;177:498-505. 
34. Bloos F, Trips E, Nierhaus A, Briegel J, Heyland DK, Jaschinski U, Moerer O, Weyland A, Marx G, Gründling $\mathrm{M}$, et al. Effect of Sodium Selenite Administration and Procalcitonin-Guided Therapy on Mortality in Patients With Severe Sepsis or Septic Shock: A Randomized Clinical Trial. JAMA Intern Med. 2016;176:1266-76.

35. Wu J, Hu L, Zhang G, Wu F, He T. Accuracy of Presepsin in Sepsis Diagnosis: A Systematic Review and Meta-Analysis. PLoS One. 2015;10:e0133057.

36. Levy MM, Fink MP, Marshall JC, Abraham E, Angus D, Cook D, Cohen J, Opal SM, Vincent JL, Ramsay G, et al. 2001 SCCM/ESICM/ACCP/ATS/SIS International Sepsis Definitions Conference. Intensive Care Med. 2003; 29: 530-8.

37. Carpio R, Zapata J, Spanuth E, Hess G. Utility of presepsin (SCD14-ST) as a diagnostic and prognostic marker of sepsis in the emergency department. Clin Chim Acta. 2015;450:169-75.

38. Wu CC, Lan HM, Han ST, Chaou CH, Yeh CF, Liu SH, Li CH, Blaney GN 3rd, Liu ZY, Chen KF. Comparison of diagnostic accuracy in sepsis between presepsin, procalcitonin, and C-reactive protein: a systematic review and meta-analysis. Ann Intensive Care. 2017;7:91.

39. Contenti J, Occelli C, Lemoel F, Ferrari P, Levraut J. Presepsin versus other biomarkers to predict sepsis and septic shock in patients with infection defined by Sepsis-3 criteria: the PREDI study of diagnostic accuracy. Emergencias. 2019;31:311-7.

\section{Figures}



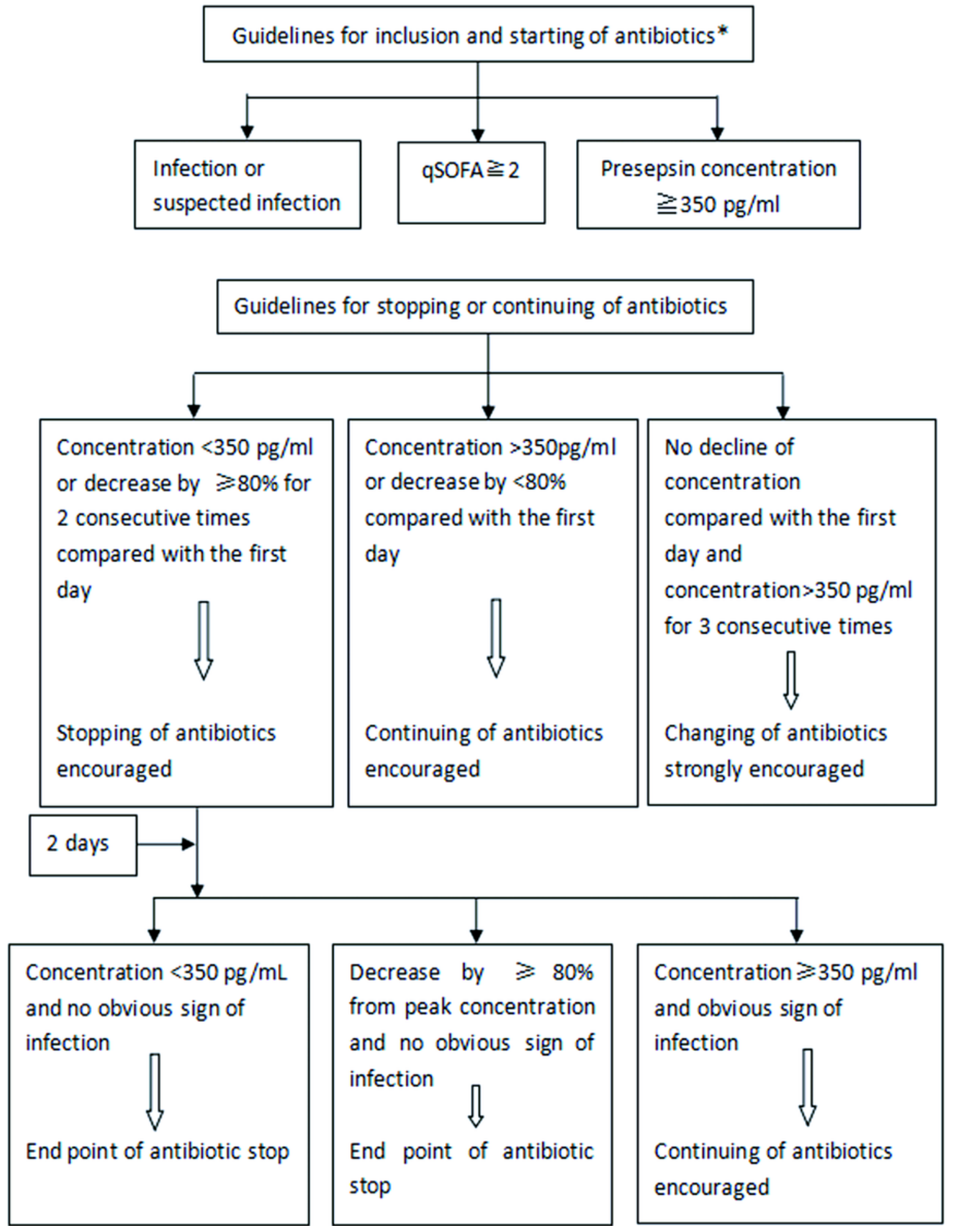

\section{Figure 1}

Guidelines of antibiotic management based on presepsin concentration *Excludes situations requiring immediate antibiotic treatment (e.g., septic shock, purulent meningitis). The presepsin concentration was obtained every other day 


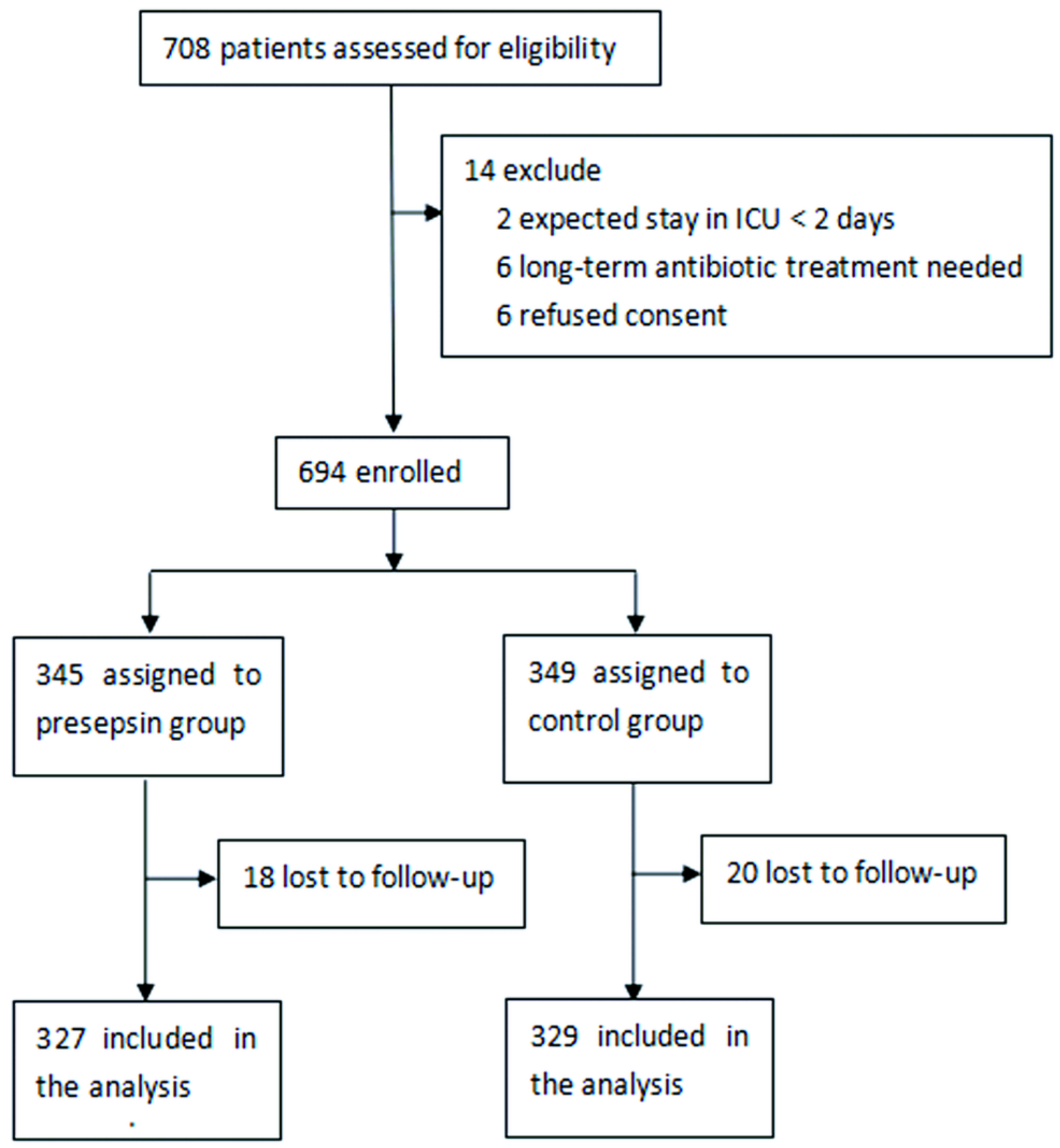

Figure 2

Study flowchart
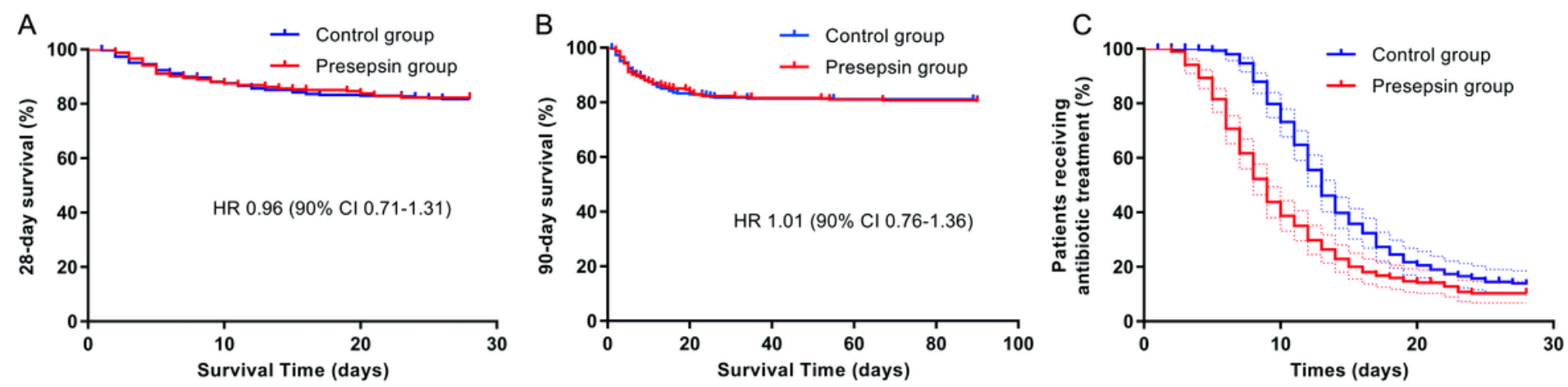


\section{Figure 3}

Survival curves. Kaplan-Meier estimates of the probability of 28-day survival (A) and 90-day survival (B) and receiving antibiotics for days 1-28 (C). HR=hazard ratio

\section{Supplementary Files}

This is a list of supplementary files associated with this preprint. Click to download.

- AdditionalTable1.doc

- AdditionalTable2.doc

- AdditionalTable3.doc

- AdditionalFig1.tif

- AdditionalFig2.tif 